\title{
Research on the Construction of Leading Innovation Capabilities and the Development of Countermeasures in Industrial Agglomeration
}

\author{
Yu Zhiyun ${ }^{1}$, Yan Haitao², Yang Mengyu ${ }^{3}$ and Hu Zhiliang ${ }^{4}$ \\ Puyang Institute of Opto-electronics Industrial Technology, Puyang, Henan 457100
}

Keywords: industrial agglomeration, leading industries, innovation capabilities

\begin{abstract}
In order to solve problems in the development of industrial agglomeration, seeking a winwin development model between industrial development and urban construction has become crucial to the construction of industrial agglomeration today. Industry, as an endogenous power, promotes the continuous development of cities, and cities are the carriers of industrial development. Urban construction provides a continuous stream of raw materials, facilities, talents and public places for industrial development; it also supports and maintains the healthy development of the industry. With the continuous advancement of China's industrialization and urbanization, the link between cities and industries are becoming closer. The problems of the rapidly developing industry are also becoming increasingly apparent; for example, the construction of industrial space is faster than the construction of urban space, and the environmental pollution caused by the production of urban space, traffic congestion, lack of public service facilities, insufficient population concentration in industrial agglomeration and public resources issues such as waste management have gradually intensified. Therefore, building a new type of industry-urban space is essential for the sustainable development and integration of industries and cities at present in order to attract outstanding companies to join industrial clusters and continuously maintain an urban business environment, which will contribute to leading industrial innovation and development.
\end{abstract}

\section{Research Background}

In the new period, China's current economic structure is dominated by industrial clusters. Competition between regions has evolved into competition between industrial clusters. Innovation is the key principle of the sustainable development of industrial clusters. General Secretary Xi Jinping pointed out that science and technology are the primary productive forces of industry, while innovation is the primary driving force for its development. It can be said that there is an inherent and inseparable connection between technological progress and the improvement of economic development, and it is a powerful leverage for the transformation of methods of production and advancing industrial structure adjustment [1]. China's economy has shifted from a high-speed growth stage to a higher-quality development stage. The mode of economic growth is also changing from a traditional factor-driven economy to an innovation-driven economy. The improvement of regional innovation capabilities has become an important measure to promote regional economic growth.

Henan, a major agricultural province in the Central Plains Economic Zone, has been making continuous efforts to realize the "integrated three transformations". As an economic zone, the planning and construction of industrial agglomeration has begun to take shape. In the new tide of changes in technological revolution and industry, technological innovation and the promotion of regional industrial and technological changes, optimization and upgrading have provided strong support for local economic development [2]. This involves mainly the implementation of the following tasks: Firstly, in order to improve innovation and development capabilities of leading industries in industrial agglomeration and also enhance the competitiveness of leading industrial enterprises, we mainly analyse how to optimize the network structure of leading industrial enterprises, how to improve their human resources, how to maximize their profit, how to accelerate the healthy development of advantageous industries, how to further attract enterprises to industrial clusters and how to truly achieve the positive effects of industrial clusters; secondly, in order to improve the development status, we mainly identify the problems and reasons that hinder the establishment of leading industrial enterprises in industrial agglomeration and provide a scientific basis for solving the 
practical problems encountered in the development of industrial agglomeration; finally, it is essential to create and take full advantage of the Internet platform in order to expand on the leading industries' innovation and development systems and policy promotion as well as to implement seamless docking services of corporate policies. Government leadership will help promote strategic alliances between leading industries and enterprises and complement each other's advantages to achieve funding, product design, production, transportation, sales, customer relationship management, the maintenance of integrated network management, reduce operating costs, enhance their ability to cope with risks, so that enterprises can get into the healthy development of the state.

\section{Theoretical Overview of Construction of Leading Industries in Industrial Agglomeration}

Industrial agglomeration is the concentration of several similar enterprises in an economic area, and the upstream and downstream supply chains and related service agencies supporting these enterprises are densely clustered together to form a strong development and continuous competitive industrial phenomenon and economic process. Industrial agglomeration is based on industrial clusters in a specific area and serves as a central space for many enterprises that produce similar products or for similar industries. According to the modern organizational theory, industrial agglomeration promotes innovation and competitiveness. It can improve the competitiveness of an industry, strengthen effective cooperation among enterprises in the industry, enhance the innovation capabilities of enterprises, promote regional economic development and fully influence resource sharing. It is also conducive to the formation of the "location brand" effect. Therefore, industrial agglomeration is the inevitable outcome of industrialization under certain conditions in a market economy and it is an important source and concentrated reflection of industrial competitiveness at this stage [3].

Since the $18^{\text {th }}$ National Congress of the Communist Party of China, the Central Committee - with General Secretary Xi Jinping at the core-has made a major decision to promote the implementation of supply-side structural reforms by focusing on de-capacity, de-stocking, deleveraging, cost reduction and other shortcomings. All these have been achieved, resulting in positive market results. To deepen the supply-side structural reforms, we must focus on the real economy, especially manufacturing, and take the improvement in the quality of the supply system as the main factor in order to improve the quality of and upgrade the existing supply, expand the high-quality incremental supply and achieve higher levels and quality of supply and demand dynamics and balance. There must be focus on accelerating the development of advanced manufacturing industries to comprehensively improve the real economy. It is necessary to accelerate the transformation and upgrading of manufacturing, accelerate the development of modern service industries and cultivate numerous world-class advanced manufacturing clusters. All of this will promote China's industry to move into the mid-to-high end of the global value chain, to consume at the mid-to-high end and also to lead innovation in green and low-carbon economy, sharing economy and modern supply chains and other areas that will foster new and good growth momentum. It is necessary to support the optimization and upgrading of traditional industries intended on advanced international standards so as to: improve product technology, process equipment, energy efficiency and environmental protection; enhance the manufacturing capabilities of basic processes, basic materials and basic parts; and improve the product quality and added value of traditional industries. It is necessary to promote the deep integration of the Internet, big data, artificial intelligence and the real economy as well as take full advantage of big data, cloud computing, artificial intelligence and the real economy's crossborder integration, innovation, quality and efficiency [4].

Promoting the construction of industrial agglomeration is a basic project to optimize the economic structure, change the development mode and achieve intensive development. It can promote the coordinated development of the "integrated three transformations" (industrialization, urbanization and agricultural modernization), and build the "three major systems" (modern industrial system, modern urban system and independent innovation system). It can serve as an effective carrier and important support for scientific development, the objectives of which are to innovate institutional mechanisms, cultivate new advantages in regional competition and implement relevant national policies and measures to promote the rise of the Central Plains Economic Zone and achieve 
leapfrogging and promotion of other key initiatives. At present, Puyang is in a critical period of accelerating the "two great leaps" and realizing the rise of the Central Plains. There are many favourable conditions and factors as well as prominent contradictions and problems, such as low industrial level, extensive development methods and intensified resource and environmental constraints. New advantages for regional development must be fostered in accordance with new paths in scientific and sustainable developments. However, the construction and development of an industrial agglomeration is a systematic project. It must stand at a strategic level through the comprehensive review of the latest domestic and foreign trends and situations, close observation of the actual situations in the region, detailed discussions, detection of problems and implementation of possible solutions and promotion of the healthy development of industrial agglomeration. At the same time, in the construction of industrial agglomeration, full consideration should be given to docking and urban development. Industrial development should rely on the promotion and development of cities and towns. Industrial agglomeration should be used to achieve urban agglomeration and its related basic support and services for urbanization, in addition to necessary conditions for industrial development.

\section{Suggestions for Innovation and Development of Leading Industries in Industrial Agglomeration}

\subsection{Strengthen the Scientific Development of Industrial Clusters}

\subsubsection{Raise Project Entry Standards}

In the process of attracting investment, the leading industry agglomeration should focus on attracting investment from enterprises with development prospects in order to prevent "high-risk, high-pollution, high-consumption and low-efficiency" projects from entering the area. As the main body of investment promotion, the government should comprehensively outline an implementation method of investment promotion for enterprises that to secure projects. With the strengthening of environmental protection work in China in recent years, the Henan Environmental Protection Bureau, in conjunction with the Provincial Development and Reform Commission, issued the "Provincial Chemical Projects and Environmental Protection Guiding Opinions Notice [Yuhuan Wen (2011) No. 72]" document, which clearly details access rules for chemical projects and clearly specifies policies and investment, site selection, clean production, pollution prevention and environmental risk prevention. Among these access rules, such as policies and investment, site selection, and the like, are additional rigid index requirements and minimum one-time fixed-asset investment requirements. Site selection cannot be established within 1.5 kilometres of a water source.

3.1.2 Accelerate the Integration of Industrial Clusters and Promote the Coordinated Division of Labour in the Industrial Value Chain

If an enterprise wants to win and maintain a competitive advantage, it depends not only on its internal value chain, but also on a larger value system (industrial value chain). The value chain of an enterprise is similar to that of its supplier, vendor and customer value chains. Each component of the industrial value chain is an organic whole that is interlinked, restricted and interdependent. Each link is composed of a large number of similar enterprises and there is a relationship between the upstream industry and downstream industry that processes large amounts of information, material and capital exchange relations in order to increase value. At the same time, industrial value chains are interconnected and often present a multi-level network structure. Under the new competitive environment, industrial competition is not only manifested between individual enterprises, but also industrial chains, enterprise clusters and even international enterprises.

\subsubsection{Improve the Service Quality of Industrial Agglomeration and Create a New Environment for} Investment and Industrial Development

It is necessary to strengthen the services of leading industrial park enterprises and create a highquality investment and management service environment. The development of industrial agglomeration must have a mechanism for continuous innovation management. There must also be a gradual change from relying on preferential policies for investment promotion to relying on 
environmental advantages, especially the soft environment, as a breakthrough. The park construction procedures should be simplified and the approval process should be reduced. The admission of park enterprises should be approved by the park management committee solely if they meet the national industrial policy and construction conditions. Subject to the overall urban planning, the detailed regulations of the park entry project should be approved by the park management committee and reported to the planning department for approval. The Environmental Impact Assessment (EIA) for the entry of a single project into the park should be simplified and the owner can choose a qualified institution to perform the EIA.

At the same time, in order to not violate the land policy, priority should be given to ensuring the use of land in the park and, if necessary, to adjust the basic farmland and overall land-use planning, and the land department should give priority in accordance with the law. For strategic parks, the paid land-use fees at the municipal level will be postponed. For enterprises investing in parks, the parks can implement a low level of investment based on the investment scale, project prospects, the number of workers, tax payments and land prices. For high-tech content and high value-added projects entering the park, the land transfer fee is allowed to be paid in instalments. Through the above measures, a conducive environment for enterprises in the industrial agglomeration is created for investment and development.

\subsection{Accelerate the Intelligentization of Industrial Agglomeration and the Deep Integration of the Internet}

According to the requirements of the "Made in China 2025 Henan Action Plan", it is necessary to implement the "Internet + collaborative manufacturing" action plan, carry out the pilots for industrial cloud computing and industrial big data innovation application, support manufacturing cloud computing platforms and resource pools and provide open and shared data mining analysis, personalization and precision marketing as well as other big data application services. Encourage backbone enterprises in industrial agglomeration to closely cooperate and fully interconnect with each link of the industrial chain through the Internet and also promote new models such as crowdsourcing design research and development and network manufacturing. Promote a seamless interconnection between Internet companies and manufacturing companies and foster new industrial Internet applications such as intelligent monitoring, remote diagnosis management and traceability in supply chains of the entire industry. Establish a cloud computing platform for intelligent manufacturing solutions and focus on displaying and promoting excellent intelligent manufacturing solutions in various industries.

Furthermore, focus on the cultivation and construction of a number of smart factories and digital workshops in the industrial agglomeration, accelerate the promotion and application of product lifecycle management, customer relationship management and supply chain management systems. Moreover, promote the group's management and control, design and manufacturing, production, supply and marketing integration and business and financial connections. The integration of other key links promotes the optimization of the manufacturing process, digital control, real-time monitoring and adaptive control of information, intelligent management and control, classified guidance, industry-specific policies, integrated application of technologies such as distributed control and manufacturing execution system for raw material companies, the popularization of lean manufacturing, agile manufacturing, virtual manufacturing and other equipment manufacturing enterprises, digital and automated technologies to create information on industrial agglomerations. The construction model of industrialization will transform the industrial agglomeration into a new type of smart park [5].

\subsection{Strengthen the Mechanism for Talent Introduction and Attach Importance to the Role of Talents in the Innovation and Development of Industrial Agglomeration}

In the new period, it is important to strengthen the training and introduction of talents and coordinate talent teams in key areas such as innovation. The creation of scientific and technological talents, technical talents, young talents and outstanding entrepreneur talents will enable the improvement of supporting policies for key talents and the development of key talents. Reforms are imperative to 
fully stimulate the innovation and creativity of various talents with the advantages of the system. Through continuous efforts, the total number of talents has continued to increase, the structure has been gradually optimized, the quality has been significantly improved, the role has been significantly exerted, the development environment has been further optimized and the overall quality of talents and their rate of contribution has been further improved.

In order to rectify the shortage of talents in the Puyang County Industrial Agglomeration Area, the following measures need to be combined to strengthen the introduction of talents:

(1) Efforts should be made to support the innovation and entrepreneurship of local graduates. Employers should be encouraged and guided to focus their needs on long-term development, formulate policies and measures that are compatible with the local resource carrying capacity of various units and also attract new graduates and young talents who return to their hometowns. The establishment of innovation and entrepreneurship platforms such as public services, business incubators, technological innovations, regional innovations and employment services in industrial agglomerations will attract innovative and entrepreneurial graduates and young talents.

(2) Improve the evaluation and incentive policies for innovative entrepreneurs. The reform of the mechanism for talent evaluation should be based on category and should full stimulate the enthusiasm for innovation and entrepreneurship in various talents. Professional and technical personnel of public institutions should be allowed and encouraged to start their own businesses, take part-time positions in technology-based enterprises, participate in collaborative innovation of enterprises and enjoy stock options and dividend incentives. Managers and scientific research personnel of restructured institutions and institutions should be allowed to hold equity in the form of "technology + cash".

(3) Enhance support for the construction of talent teams for private enterprises and newlyestablished small- and medium-sized enterprises. Further support should be given to the construction of scientific and technological innovation talent training bases, high-skilled talent training bases, rural revitalization of practical talent training bases and double-innovation talent training bases; there should also be a continuous effort to provide support for certain policy and project funding for significant work success.

(4) Improve the security policy for attracting reserve talents. Provide high quality and convenient services for high-level talents, urgently needed talents and graduates' accommodation. Improve college students' entrepreneurship, counselling and flexible education system management methods. Revise the subsidy and support policies for innovation and entrepreneurship of college students and graduates within 5 years of graduation. Coordinate the advantageous resources of all parties and effectively protect the demand for high-level talents and urgently needed accommodation through market leasing, monetized resettlement, and provision of apartments. Coordinate with education institutions at all levels to effectively solve high-level problems and urgently needed children's education. At the same time, it is necessary to strengthen the "one-on-one" service guarantee for doctors and academicians in Puyang and also explore the establishment of a "one-to-one" service guarantee system for experts at all levels.

\section{Funded project:}

Soft science research program of Henan province. Research on the Construction of Leading Innovation Capabilities and the Development of Countermeasures in Industrial Agglomeration; Funded project number: 182400410063

\section{About the Authors:}

1. Yu Zhiyun, an intermediate engineer, is currently the Director of the Institute. Research direction: Research and development and mass production of fiber Bragg grating, during which 6 patents for invention were applied.

Email: 15991736147@163.com. 
2. Yan Haitao is a Professor at the Henan University of Science and Technology and concurrently President of the Institute. He has published more than 30 Science Citation Index (SCI) and Engineering Index (EI) retrieval papers, applied for 26 patents and software copyrights, have nine authorized patents, and two book publications. Research direction: Transformation from basic research to engineering technology.

Email: yanhaitaoyht@163.com.

3. Yang Mengyu, a junior engineer, is currently the Director of the Office of the Academy. Email: 13183181820@163.com.

4. Hu Zhiliang, a junior engineer, is currently the Research Secretary of the Research Institute. During the period, he applied for three patents and authorized one.

Email: 13949728201@163.com.

\section{References}

[1] He Wentao. "The impact of industrial agglomeration on the initial scale selection and sustainable survival of enterprises: based on the analysis of SMEs in Liaoning Province". Economic Geography, 2019, 39(10): 112-122.

[2] Yuan Chenguang, Liang Liutao, Tang Linhao, Chen Changyou \& Ma Junfang. "Analysis on the Spatial Difference of Land Economic Density in Industrial Agglomeration in Henan Province". Areal Research and Development, 2019, 38(05): 25-29, 40.

[3] Zhu Songlin. Make up for the shortcomings, extend the chain, and provide strong services. Henan's industrial agglomeration continue to promote "second entrepreneurship."

[4] Liu Hedong \& Chen Lei. "Research on Evolution Mechanism of Ecosystem in Agglomeration Area of High-Tech Industries”. Science and Technology Management Research, 2019, 39(16): 199-204.

[5] Liu Yong \& Du Junliang. "Research on Agglomeration Effect and Diffusion Mechanism of Regional Creative Industry". Research on Generalized Virtual Economy, 2019, 10(02): 59-66. 